\title{
SAM UPDATING USING MULTIOBJECTIVE OPTIMIZATION TECHNIQUES
}

\author{
D.R. Santos Peñate ${ }^{1}$, C. Manrique de Lara Peñate ${ }^{2}$ \\ ${ }^{1}$ Departamento de Métodos Cuantitativos en E. y G. \\ Universidad de Las Palmas de G.C., 35017 Las Palmas de G.C., Spain \\ E-mail: drsantos@empresariales.ulpgc.es \\ ${ }^{2}$ Departamento de Análisis Económico Aplicado \\ Universidad de Las Palmas de G.C., 35017 Las Palmas de G.C., Spain \\ E-mail: casiano@empresariales.ulpgc.es
}

\begin{abstract}
In this work we present an adjustment/updating procedure of Social Accounting Matrices (SAM) using multiobjective optimization techniques. The usual setting concentrates the adjustment effort in either the column or row coefficients of the SAM. The normal tendency consists in using the column coefficients because they better reflect the technical coefficients embedded in the SAM. Using the benchmark SAM as the basis, and incorporating the new information available we pose a double-objective optimization problem and apply the method of compromise programming that allow us to work together with column and row coefficients.

We present samples of the adjustment procedure where we show and compare the Pareto optimal solutions obtained together with other solutions obtained with different adjustment criteria. We compare the results obtained with the ones obtained with other approaches like RAS and the minimum sum of cross entropy together with other methods proposed by the authors. This comparison allows us to evaluate the differences existing between these different methods and the pure vertical or horizontal adjustment criteria. We believe that the adjustment/updating criteria used does not need to be the same along the different parts of the SAM.

We may want to update the input-output matrix included in the SAM concentrating in the vertical/column/technical coefficients. But there may be other parts of the SAM where we think that the use of row coefficients, or together both row and column coefficients, is more appropriate. The method we propose can be also applied to situations where the adjustment criteria is not the same for different parts of the SAM.
\end{abstract}




\section{Introduction}

A Social Accounting Matrix (SAM) is a square matrix whose rows and columns represent the resources and uses of separate economic accounts which together summarize the basic flows within the different groups of transactors or categories of transactions in an economy. The incomings (rows) and outgoings (columns) are necessarily equilibrated following standard economic accounting standards, therefore the sum of columns and rows for each account must be the same. This matrix presents an accounting system that provides information about aspects of an economy like the structure, composition and level of production, the value added generated by the factors of production and the distribution of income among different groups of households. Normally, a SAM is constructed using an Input-Output Table as starting point and includes figures about consumption, the structure of production, and the flows related to foreign trade, savings and investment.

The adjustment of a SAM consists in determining the SAM corresponding to period $\mathrm{t}=\mathrm{T}$ starting from a known SAM, which corresponds to moment $\mathrm{t}=0$, and from certain available information about the SAM in moment $\mathrm{t}=\mathrm{T}$. It is a question of finding a SAM $\mathrm{X}^{\mathrm{T}}$ whose structure is, in a certain sense, as close as possible to the structure of $\backslash$ the $\mathrm{SAM}$ in moment $\mathrm{t}=0, \mathrm{X}^{0}$. Normally this structure is defined in terms of the row (horizontal) coefficients and the column (vertical) coefficients, assuming that if element $\mathrm{x}_{\mathrm{ij}}^{0}$ of the initial matrix is null then the corresponding element $\mathrm{x}_{\mathrm{ij}}^{\mathrm{T}}$ of the final matrix is also null. If $X=\left(x_{i j}\right)_{1 \leq i, j} \leq n$ is a $S A M$ and $S=\left\{(i, j): x_{i j} \neq 0\right\}$, then the matrix of row coefficients, $A=\left(a_{i j}\right)_{1 \leq i, j \leq n}$, and that of column coefficients, $B=\left(b_{i j}\right)_{1 \leq i, j} \leq n$, can be defined as

$$
\begin{array}{ll}
a_{i j}=\frac{x_{i j}}{\sum_{j} x_{i j}} & \text { if }(\mathrm{i}, \mathrm{j}) \in \boldsymbol{S} \text {, and } \mathrm{a}_{\mathrm{ij}}=0 \text { if }(\mathrm{i}, \mathrm{j}) \notin \boldsymbol{S} \\
b_{i j}=\frac{x_{i j}}{\sum_{i} x_{i j}} & \text { if }(\mathrm{i}, \mathrm{j}) \in \boldsymbol{S} \text {, and } \mathrm{b}_{\mathrm{ij}}=0 \text { if }(\mathrm{i}, \mathrm{j}) \notin \boldsymbol{S}
\end{array}
$$

We consider that the adjustment objective consists in determining a SAM $\mathrm{X}^{\mathrm{T}}$ such that the ratios $\frac{a_{i j}^{T}}{a_{i j}^{0}}$, or $\frac{b_{i j}^{T}}{b_{i j}^{0}}$, for $(\mathrm{i}, \mathrm{j}) \in \boldsymbol{S}$, as similar as possible to unity, distinguishing between two types of adjustment, the horizontal and the vertical one, depending on wether we approximate the ratios of horizontal or vertical coefficients to unity. The definition of the concept of proximity determines the adjustment criterium. In this paper we use the following criteria for each of the adjustment types (horizontal and vertical):

- METL1: METL1H, METL1V and METL1HV.

$$
F H_{1}\left(A^{T}, A^{0}\right)=\sum_{(i, j) \in S}\left|\frac{a_{i j}^{T}}{a_{i j}^{0}}-1\right| .
$$




$$
\begin{aligned}
& F V_{1}\left(B^{T}, B^{0}\right)=\sum_{(i, j) \in S}\left|\frac{b_{i j}^{T}}{b_{i j}^{0}}-1\right| . \\
& F H V_{1}=F H_{1}\left(A^{T}, A^{0}\right)+F V_{1}\left(B^{T}, B^{0}\right)
\end{aligned}
$$

- METL2: METL2H, METL2V and METL2HV.

$$
\begin{aligned}
& F H_{2}\left(A^{T}, A^{0}\right)=\sum_{(i, j) \in S}\left(\frac{a_{i j}^{T}}{a_{i j}^{0}}-1\right)^{2} \cdot \\
& F V_{2}\left(B^{T}, B^{0}\right)=\sum_{(i, j) \in S}\left(\frac{b_{i j}^{T}}{b_{i j}^{0}}-1\right)^{2} \cdot \\
& F H V_{2}=F H_{2}\left(A^{T}, A^{0}\right)+F V_{2}\left(B^{T}, B^{0}\right)
\end{aligned}
$$

- MMAX: MMAXH, MMAXV and MMAXHV.

$$
\begin{aligned}
& F H_{3}\left(A^{T}, A^{0}\right)=\sum_{(i, j) \in S}\left|\frac{a_{i j}^{T}}{a_{i j}^{0}}-1\right|+|S| \max _{(i, j) \in S}\left|\frac{a_{i j}^{T}}{a_{i j}^{0}}-1\right| \\
& F V_{3}\left(B^{T}, B^{0}\right)=\sum_{(i, j) \in S}\left|\frac{b_{i j}^{T}}{b_{i j}^{0}}-1\right|+|S| \max _{(i, j) \in S}\left|\frac{b_{i j}^{T}}{b_{i j}^{0}}-1\right| \\
& F H V_{3}=F H_{3}\left(A^{T}, A^{0}\right)+F V_{3}\left(B^{T}, B^{0}\right)
\end{aligned}
$$

- RAS: RASH, RASV and RASHV.

$$
\begin{aligned}
& F H_{4}\left(A^{T}, A^{0}\right)=\sum_{(i, j) \in S} \frac{\gamma_{i}}{\gamma} a_{i j}^{T} \ln \frac{a_{i j}^{T}}{a_{i j}^{0}} \\
& F V_{4}\left(B^{T}, B^{0}\right)=\sum_{(i, j) \in S} \frac{\gamma_{i}}{\gamma} b_{i j}^{T} \ln \frac{b_{i j}^{T}}{b_{i j}^{0}} \\
& F H V_{4}=F H_{4}\left(A^{T}, A^{0}\right)+F V_{4}\left(B^{T}, B^{0}\right)
\end{aligned}
$$


- MSCE: MSCEH, MSCEV and MSCEHV.

$$
\begin{aligned}
& F H_{5}\left(A^{T}, A^{0}\right)=\sum_{(i, j) \in S} a_{i j}^{T} \ln \frac{a_{i j}^{T}}{a_{i j}^{0}} \\
& F V_{5}\left(B^{T}, B^{0}\right)=\sum_{(i, j) \in S} b_{i j}^{T} \ln \frac{b_{i j}^{T}}{b_{i j}^{0}} \\
& F H V_{5}=F H_{5}\left(A^{T}, A^{0}\right)+F V_{5}\left(B^{T}, B^{0}\right)
\end{aligned}
$$

Where $\gamma_{i}=\sum_{j} x_{i j}$ and $\gamma=\sum_{i} \gamma_{i}$. Therefore $\gamma_{i}$ is the sum of the elements of row $i$, which is equal to the sum of the elements of column $i$, and $\gamma$ is the sum of all the elements of matrix $\mathrm{X}^{0}$.

The adjustment problem is formulated as an optimization problem where the objective function is one of the previously mentioned and the restrictions are determined by the column and row totals, which are supposed to be known, in addition to other given values.

The vertical criterium $\mathrm{FV}_{1}$ has been used by Matuszewski, Pitts and Sawyer (1964). Criterium FV 4 corresponds to the well known RAS algorithm and $\mathrm{FV}_{5}$ is based on an entrophy measure which has been used by Golan, Judge and Robinson (1994), and Robinson, Cattaneo and El-Said(2000), among others. Criteria $\mathrm{FV}_{4}$ and $\mathrm{FV}_{5}$ are particular cases of the adjustment criterium of the minimization of the sum of weighted crossed entropies (McDougall, 1999).

In this paper we combine both the vertical and the horizontal adjustment criteria applying multiobjective optimization techniques. We will develop an adjustment method using criteria METL1H and METL1V ( $\mathrm{FH}_{1}$ and $\left.\mathrm{FV}_{1}\right)$, which define a biobjective problem. For the examples we put forward, we will calculate different Pareto optimal solutions and the compromise set. We will represent this solutions, together with the ones obtained with other adjustment criteria in the space of the 3 objectives and analyze the results obtained. The rest of the paper is organized as follows. In section 2 we present the compromise programming approach applied to the adjustment of Social Accounting Matrices. In section 3 we illustrate this adjustment method with different examples. In section 4 we discuss the adjustment problem when the criteria are not the same for all sectors. Finally, in section 5 we include some conclusions and possible extensions of our work.

\section{Adjustment of a SAM using compromise programming}

In most of the SAM adjustment efforts, only vertical coefficients are used disregarding the horizontal adjustment. On the other hand, the adjustment criteria commonly used can be classified into two groups. In the first group we can find the criteria based in the minimization of a certain metric $L_{p}$, while we can find in the second group those defined starting with an entropy measure. Criteria METL1, METL2 and MMAX, defined in section 1, belong to the first group (involve metrics $\mathrm{L}_{1}, \mathrm{~L}_{2}$ and $\mathrm{L}_{\infty}$ ). The RAS and MSCE criteria belong to the second group.

The criteria METL1, METL2 and MMAX can be expressed in the form $L_{1}(U, C), L_{2}(U, C)$ and $L_{1}(U, C)+|\mathrm{S}| L_{\infty}(U, C)$ respectively, being $\mathrm{U}$ the square matrix of order $\mathrm{n}$ whose elements are all 
equal to one, and $\mathrm{C}$ the square matrix of order $\mathrm{n}$ whose element $(\mathrm{i}, \mathrm{j}), \mathrm{c}_{\mathrm{ij}}$, is equal to the ratio of coefficients (horizontal or vertical) in moment $\mathrm{t}=\mathrm{T}$ and $\mathrm{t}=0$, if $(\mathrm{i}, \mathrm{j}) \in \boldsymbol{S}$ is non null, and $\mathrm{c}_{\mathrm{ij}}=1$ otherwise.

The entropy minimization criterium (WMSCE) consists in the minimization of the function

$$
E_{w}(C)=\sum_{(i, j) \in S} w_{i j} c_{i j}^{T} \ln \frac{c_{i j}^{T}}{c_{i j}^{0}}
$$

where $w_{i j}$ are positive weights. RAS results from making $w_{i j}=\frac{\gamma_{j}^{T}}{\gamma^{T}}$ in the vertical adjustment and $w_{i j}=\frac{\gamma_{i}^{T}}{\gamma^{T}}$ in the horizontal one, while the MSCE criterium can be obtained by making $w_{i j}=1, \forall(\mathrm{i}, \mathrm{j})$.

Considering that the preservation of the horizontal structure, together with the vertical one, can take part in the adjustment objectives, being for some sectors even the most important of both criteria, and starting from the original approach of Matuszewski, Pitts and Sawyer, who applied the vertical adjustment with metric $\mathrm{L}_{1}$, we pose a biobjective problem where we combine both the vertical and horizontal adjustment. This biobjective can be expressed as follows

$$
\min f(X)=\left(f_{1}(X) ; f_{2}(X)\right)
$$

subject to:

$$
\begin{aligned}
& \sum_{j} x_{i j}=\gamma_{i}, i=1, \ldots, n \\
& \sum_{i} x_{i j}=\gamma_{j}, j=1, \ldots, n \\
& x_{i j}=0, \forall(\mathrm{i}, \mathrm{j}) \notin S \\
& x_{i j} \geq 0, \forall(\mathrm{i}, \mathrm{j})
\end{aligned}
$$

being

$$
\begin{array}{r}
f_{1}(X)=\sum_{(i, j) \in S}\left|\frac{a_{i j}}{a_{i j}^{0}}-1\right| \\
f_{2}(X)=\sum_{(i, j) \in S}\left|\frac{b_{i j}}{b_{i j}^{0}}-1\right| \\
a_{i j}=\frac{x_{i j}}{\gamma_{i}}, b_{i j}=\frac{x_{i j}}{\gamma_{j}}, \forall(i, j) \in S
\end{array}
$$


The last restriction in (2) can be eliminated because it is a lineal combination of restrictions (1) and the rest in (2). Introducing new variables, the problem can be stated as a lineal program resulting the following equivalent problem:

$$
\min g(X)=\left(g_{1}\left(X, Y^{h}, Z^{h}, Y^{v}, Z^{v}\right), g_{2}\left(X, Y^{h}, Z^{h}, Y^{v}, Z^{v}\right)\right)
$$

subject to:

$$
\begin{aligned}
& \sum_{j} x_{i j}=\gamma_{i}, i=1, \ldots, n \\
& \sum_{i} x_{i j}=\gamma_{j}, j=1, \ldots, n-1 \\
& \frac{a_{i j}}{a_{i j}^{0}}-1=y_{i j}^{h}-z_{i j}^{h}, \forall(i, j) \in S \\
& \frac{b_{i j}}{b_{i j}^{0}}-1=y_{i j}^{v}-z_{i j}^{v}, \forall(i, j) \in S \\
& x_{i j}=0, \forall(\mathrm{i}, \mathrm{j}) \notin S \\
& x_{i j}, y_{i j}^{h}, z_{i j}^{h}, y_{i j}^{v}, z_{i j}^{v} \geq 0, \forall(\mathrm{i}, \mathrm{j}) \in S
\end{aligned}
$$

being

$$
\begin{gathered}
g_{1}\left(X, Y^{h}, Z^{h}, Y^{v}, Z^{v}\right)=\sum_{(i, j) \in S}\left(y_{i j}^{h}+z_{i j}^{h}\right) \\
g_{2}\left(X, Y^{h}, Z^{h}, Y^{v}, Z^{v}\right)=\sum_{(i, j) \in S}\left(y_{i j}^{v}+z_{i j}^{v}\right) \\
a_{i j}=\frac{x_{i j}}{\gamma_{i}}, b_{i j}=\frac{x_{i j}}{\gamma_{j}}, \forall(i, j) \in S
\end{gathered}
$$

where $X=\left(x_{i j}\right), Y^{h}=\left(y_{i j}^{h}\right), Z^{h}=\left(z_{i j}^{h}\right), Y^{v}=\left(y_{i j}^{v}\right), Z^{h}=\left(z_{i j}^{v}\right)$

A way to obtain Pareto optimal solutions consists in minimizing a weighted sum of the objectives with strictly positive weights, adding the before mentioned restrictions. The ideal point results from minimizing each objective separately, taking each of the optimal solutions obtained. Applying the method of the restrictions we can obtain the payment matrix with the Pareto optimal solutions corresponding to the ideal values.

The ideal point, whose components are the minimal values of each of the objectives, is normally not attainable (if not there would be no conflict between the different objectives). One of the approaches of the multiobjective optimization is based on the idea that the best options are those 
feasible solutions which lie near to the ideal point in the objective space. This idea is the base of compromise programming ( $\mathrm{Yu}$ (1973) and Zeleny (1973)). The compromise set is formed by the optimal solutions(optimal values in the objective space) of the problems of the minimization of the $\mathrm{L}_{\mathrm{p}}$ (normalized) distances to the ideal point. The optimal solutions of the problems of minimization of distances $L_{p}$ with $1 \leq p \leq \infty$ are Pareto optimal. For $p=\infty$ these solutions are only weak Pareto optimal and there always exist at least one Pareto optimal. For lineal programs, the solutions to the problems for $1<p<\infty$ are located between the solutions obtained for $p=1$ and $p=\infty$.

\section{Examples}

In order to show an application of the compromise programming applied to the adjustment of Social Accounting Matrices, we present three examples where the benchmark matrix, $\mathrm{X}^{0}$, is a matrix of order $12 \times 12$ generated by the aggregation of certain sectors in the SAM of Mozambique of year 1994 as appears in Robinson, S., A. Cataneo and M. El-Said (2001). We consider three cases, cases $\mathrm{a}, \mathrm{b}$ and $\mathrm{c}$, which result from taking different values for the sums of the elements in the columns of $\mathrm{X}^{\mathrm{T}}$. The value of these three new column totals and the increase the new values represent from the benchmark elements of matrix $\mathrm{X}^{0}$, appear in table 1 . While in case a the increments lie between a $2.04 \%$ and a $9.41 \%$, in cases $b$ and c these increments vary between a $0.89 \%$ and a $53.06 \%$, and a $0.12 \%$ and a $58.36 \%$ respectively. The equalities:

$$
\frac{a_{i j}^{T}}{a_{i j}^{0}}=\frac{b_{i j}^{T}}{b_{i j}^{0}} \frac{\frac{\gamma_{j}^{T}}{\gamma_{i}^{T}}}{\frac{\gamma_{j}^{0}}{\gamma_{i}^{0}}},(i, j) \in S
$$

relate the horizontal with the vertical coefficients. These relations seem to show that if the ratios $\frac{\frac{\gamma_{j}^{T}}{\gamma_{i}^{T}}}{\frac{\gamma_{j}^{0}}{\gamma_{i}^{0}}}$

which appear in (3) are very different the conflict between the horizontal and vertical adjustment is higher.

In case a the minimum and maximum values of ratios $\frac{\gamma_{i}}{\gamma_{j}}$ for the initial matrix are 0.07 and 51.14 respectively, while for the final matrix these values are 0.06 and 54.83. The differences, in relation to these extreme values, between matrices $X^{0}$ and $X^{T}$ are higher in cases $b$ and $c$. In case $b$ the extreme values for the final matrix are 0.1 and 35 , and in case c result to be 0.07 and 58.33. The quotient of ratios $\frac{\gamma_{i}}{\gamma}$ that figure in (3) vary between 0.9408 and 1.0723 in case a, 0.6592 and 1.4112 in case $b$, and 0.6447 and 1.5817 in case $c$. 
Table 2 contains the ideal point and the payments matrix for each case. The values of this payment matrix correspond with Pareto optimal solutions where one of the objectives achieves the ideal value.

Figures 1 to 6 show the ideal point, the compromise set and solutions corresponding to criteria METL2, MMAX, RAS and MSCE, in the space of the objectives. Tables 3, 4 and 5, contain the coordinates of the Pareto optimal points corresponding to the ideal values of each objective, the extreme points of the compromise set and the solutions corresponding to the different criteria considered. The same tables show the relative distance measures between the initial matrices, for both the vertical and horizontal coefficients.

If we analyze the results we can observe that criteria RASH, RASV and RASHV achieve the same solution. On the other hand, in the space of the objectives, while in cases a and b criteria METL2 and MMAX give solutions that are nearer to the solutions of METL1 than the criteria based on an entrophy measure, in case $\mathrm{c}$ the solution MMAX is the most distant, probably due to the weight assigned to the minimax component that produces a higher influence on it than the $\mathrm{L}_{1}$ component. It can also be perceived that the vertical and horizontal adjustments do not coincide for all the criteria, in the sense that the vertical solution for a criterium can achieve a vertical value for METL1 that is worse tan the horizontal solution. Thus, for example, in case a the solution of the MSCEV has a value for the vertical objective that is worse than the solution of MSCEH and MSCEHV. Something similar occurs in case c with the MMAXH criterium and the horizontal objective value.

\section{$4 \quad$ Adjustment criteria by sectors}

There may exist situations where we may need to put forward a vertical adjustment for certain sectors while for others we should pursue a horizontal adjustment. In this case, the methods that use only either vertical or horizontal coefficients may result inadequate and it seems necessary to combine both types of adjustment. These situations can be undertaken considering two objectives corresponding to the horizontal and vertical adjustment, in such a way that the sectors that have to be adjusted horizontally appear in first objective while those needing a vertical objective are introduced in the second one. The sectors for which the most suitable adjustment is not settled could figure in both objectives. If $\mathrm{H}\}$ and $\mathrm{V}$ represent, respectively, the sectors to which a horizontal and vertical adjustment has to be applied, the objectives of the problem for adjustment criterium METL1 can be formulated in the following way:

$$
f_{1}(X)=\sum_{(i, j) \in S, i \in \mathrm{H} \cup R}\left|\frac{a_{i j}}{a_{i j}^{0}}-1\right|, f_{2}(X)=\sum_{(i, j) \in S, j \in V \cup R}\left|\frac{b_{i j}}{b_{i j}^{0}}-1\right|,
$$

donde $R=S-(H \cup V)$ 


\section{Conclusions}

In this work we propose an adjustment method for the adjustment of Social Accounting Matrices that combine a horizontal adjustment with a vertical one. We formulate the adjustment problem as a multiobjective optimization problem that we solve applying compromise programming, using the adjustment criteria of the minimization of distance $\mathrm{L}_{1}$ (METL1). Each objective corresponds to one of the types of adjustment, vertical and horizontal. To illustrate the adjustment method and in order to show the position of the solutions obtained be other criteria in the space on objectives, we consider other criteria based in metrics Lp (METL2 and MMAX) and the entrophy concept (RAS and MSCE). Taking as the initial matrix the matrix of order $12 \times 12$ generated by the aggregation of certain sectors in the SAM of Mozambique of year 1994 as appears in Robinson, S., A. Cataneo and M. El-Said (2001), we present several examples created by considering different values for the sum of the elements of the columns of the searched new matrix. It can be observed that the solutions obtained by RASV, RASH and RASHV coincide, and that the solution of the vertical adjustment for criterium MSCE does not necessarily correspond with the best value for the vertical objective within those obtained by the solutions achieved by this criterium. The position of the MMAX solutions in case 3 probably owes to the fact that there is a dominant influence of the minimax component with respect of the $\mathrm{L}_{1}$ component, produced by the weights used.

This work can be extended in different ways. Between other aspects, one could study the usefulness of the multiobjective optimization techniques in situations where the adjustment criterium is not the same for all sectors. The results of applying the proposed adjustment method to other criteria could be also analyzed.

\section{References}

Golan, Judge and Miller(1996). Maximum entrophy econometrics, robust estimation with limited data. John Wiley \& Sons.

Golan, Judge and Robinson (1994): Recovering information from incomplete or partial multisectorial economic data. The Review of Economics and Statistics, 76, 541-549.

Harrigan, F.J. and I. Buchanan (1984): A quadratic programming approach to IO estimation and simulation. Journal of Regional Science, 24, 3, 339-358.

Lahr, M.L. (1998): A strategy for producing hybrid regional input-output tables.

Macgill, S.M. (1977): Theoretical properties of biproportional matrix adjusment. Environment and Planning A, 9, 687-701.

Matuszewski, T.I., P.R. Pitts and J.A. Sawyer (1964): Linear programming estimates of changes in input coefficients. Canadian Journal of Economics and Political Science 2, 203-210.

McDougall, R.A. (1999): Entropy theory and RAS are friends. http: //www.sjfi.dk/gtap /papers $/ M c D o u g a l l . p d f\}$.

Miettinen, K.M. (1999). Nonlinear multiobjective optimization. Kluwer.

Robinson, S., A. Cataneo and M. El-Said (2001): Updating and estimating a social accounting matrix using cross entrophy methods. Economic Systems Research, 13, 1, 47-64. 
Yu, P.L. (1973): A class of solutions for group decision problems. Management Science, 19, 8, 936-946.

Zeleny,M. (1973): Compromise programming. Multiple criteria decision making. Edited by J.L. Cochrane, M. Zeleny, University of South Carolina Press, Columbia, South Carolina, 262-301. 


\begin{tabular}{|c|c|c|c|c|c|c|c|c|c|c|c|c|}
\hline COLUMNS & 1 & 2 & 3 & 4 & 5 & 6 & 7 & 8 & 9 & 10 & 11 & 12 \\
\hline Total $\mathrm{X}^{0}$ & 55.83 & 221.02 & 43.79 & 300.69 & 155.75 & 62.86 & 155.38 & 22.53 & 5.88 & 33.94 & 44.12 & 83.9 \\
\hline Total $X^{T}-a$ & 60 & 241 & 47 & 329 & 167 & 65 & 163 & 23 & 6 & 35 & 46 & 91 \\
\hline (\%) Increase & 7.47 & 9.04 & 7.33 & 9.41 & 7.22 & 3.40 & 4.90 & 2.09 & 2.04 & 3.12 & 4.26 & 8.46 \\
\hline Total $X^{\mathrm{T}}-\mathbf{b}$ & 57 & 223 & 47 & 315 & 160 & 70 & 161 & 25 & 9 & 40 & 49 & 91 \\
\hline (\%) Increase & 2.09 & 0.89 & 7.33 & 4.76 & 2.73 & 11.36 & 3.62 & 10.96 & 53.06 & 17.85 & 11.06 & 8.4 \\
\hline Total $X^{T}-c$ & 57 & 350 & 45 & 305 & 156 & 63 & 200 & 25 & 6 & 35 & 45 & 84 \\
\hline (\%) Increase & 2.09 & 58.36 & 2.76 & 1.43 & 0.16 & 0.22 & 28.72 & 10.96 & 2.04 & 3.12 & 1.99 & 0.12 \\
\hline
\end{tabular}

Table 1: Column totals in cases a, b and c

\begin{tabular}{|c|c|c|}
\hline \multirow[t]{2}{*}{ Case } & \multicolumn{2}{|c|}{ Objective } \\
\hline & Horizontal & Vertical \\
\hline \multirow{5}{*}{$\mathbf{a}$} & \multicolumn{2}{|c|}{ Ideal Point } \\
\hline & 1.9385 & 1.9483 \\
\hline & \multicolumn{2}{|c|}{ Payments Matrix } \\
\hline & 1.9388 & 2.4892 \\
\hline & 2.4241 & 1.9483 \\
\hline \multirow{5}{*}{ b } & \multicolumn{2}{|c|}{ Ideal Point } \\
\hline & 2.2242 & 2.2194 \\
\hline & \multicolumn{2}{|c|}{ Payments Matrix } \\
\hline & 2.2242 & 4.0137 \\
\hline & 4.0620 & 2.2194 \\
\hline \multirow{5}{*}{ c } & \multicolumn{2}{|c|}{ Ideal Point } \\
\hline & 49.3945 & 57.9231 \\
\hline & \multicolumn{2}{|c|}{ Payments Matrix } \\
\hline & 49.3945 & 60.0296 \\
\hline & 50.6328 & 57.9231 \\
\hline
\end{tabular}

Table 2: Ideal points and payments matrices 


\begin{tabular}{|c|c|c|c|c|c|c|c|}
\hline \multirow[b]{2}{*}{ Solutions } & \multicolumn{2}{|c|}{ Objectives } & \multicolumn{5}{|c|}{ Measures (for vertical and horizontal coefficients) } \\
\hline & Horizontal & Vertical & $\mathbf{L}_{1}$ & $\mathbf{L}_{2}$ & MSCE & RAS & $\mathbf{L}_{\infty}$ \\
\hline paymm1 & 1.94 & 2.49 & $\begin{array}{l}0.0173 \\
0.0135\end{array}$ & $\begin{array}{l}0.0074 \\
0.0074\end{array}$ & $\begin{array}{l}0.0585 \\
0.0303\end{array}$ & $\begin{array}{l}0.0040 \\
0.0040\end{array}$ & $\begin{array}{l}1.0000 \\
1.0000\end{array}$ \\
\hline paymm2 & 2.42 & 1.95 & $\begin{array}{l}0.0135 \\
0.0168 \\
\end{array}$ & $\begin{array}{l}0.0073 \\
0.0074 \\
\end{array}$ & $\begin{array}{l}0.0546 \\
0.0297 \\
\end{array}$ & $\begin{array}{l}0.0039 \\
0.0039 \\
\end{array}$ & $\begin{array}{l}0.9931 \\
0.9928 \\
\end{array}$ \\
\hline compr1 & 2.06 & 2.22 & $\begin{array}{l}0.0154 \\
0.0143\end{array}$ & $\begin{array}{l}0.0073 \\
0.0073\end{array}$ & $\begin{array}{l}0.0545 \\
0.0285\end{array}$ & $\begin{array}{l}0.0037 \\
0.0037\end{array}$ & $\begin{array}{l}0.9897 \\
0.9893\end{array}$ \\
\hline compr2 & 2.12 & 2.15 & $\begin{array}{l}0.0150 \\
0.0147\end{array}$ & $\begin{array}{l}0.0073 \\
0.0073\end{array}$ & $\begin{array}{l}0.0545 \\
0.0286\end{array}$ & $\begin{array}{l}0.0037 \\
0.0037\end{array}$ & $\begin{array}{l}0.9897 \\
0.9893\end{array}$ \\
\hline met12v & 3.13 & 2.88 & $\begin{array}{l}0.0200 \\
0.0217\end{array}$ & $\begin{array}{l}0.0057 \\
0.0058\end{array}$ & $\begin{array}{l}0.0273 \\
0.0237 \\
\end{array}$ & $\begin{array}{l}0.0017 \\
0.0017\end{array}$ & $\begin{array}{l}0.5669 \\
0.5522\end{array}$ \\
\hline met12h & 2.8460 & 3.0783 & $\begin{array}{l}0.0214 \\
0.0198\end{array}$ & $\begin{array}{l}0.0057 \\
0.0057\end{array}$ & $\begin{array}{l}0.0277 \\
0.0227\end{array}$ & $\begin{array}{l}0.0017 \\
0.0017\end{array}$ & $\begin{array}{l}0.5767 \\
0.5623\end{array}$ \\
\hline met12vh & 2.95 & 2.97 & $\begin{array}{l}0.0207 \\
0.0205\end{array}$ & $\begin{array}{l}0.0057 \\
0.0057\end{array}$ & $\begin{array}{l}0.0275 \\
0.0231\end{array}$ & $\begin{array}{l}0.0017 \\
0.0017\end{array}$ & $\begin{array}{l}0.5721 \\
0.5576\end{array}$ \\
\hline Mmaxv & $\overline{3.44}$ & $\overline{3.07}$ & $\begin{array}{l}0.0213 \\
0.0239\end{array}$ & $\begin{array}{l}0.0063 \\
0.0065\end{array}$ & $\begin{array}{l}0.0381 \\
0.0345\end{array}$ & $\begin{array}{l}0.0021 \\
0.0021\end{array}$ & $\begin{array}{l}0.3551 \\
0.4233\end{array}$ \\
\hline Mmaxh & 2.93 & 3.42 & $\begin{array}{l}0.0237 \\
0.0204\end{array}$ & $\begin{array}{l}0.0062 \\
0.0063\end{array}$ & $\begin{array}{l}0.0361 \\
0.0307\end{array}$ & $\begin{array}{l}0.0019 \\
0.0019 \\
\end{array}$ & $\begin{array}{l}0.3817 \\
0.3608 \\
\end{array}$ \\
\hline Mmaxvh & 3.16 & 3.14 & $\begin{array}{l}0.0218 \\
0.0220\end{array}$ & $\begin{array}{l}0.0062 \\
0.0063\end{array}$ & $\begin{array}{l}0.0348 \\
0.0306\end{array}$ & $\begin{array}{l}0.0019 \\
0.0019\end{array}$ & $\begin{array}{l}0.3755 \\
0.3642\end{array}$ \\
\hline Rasv & 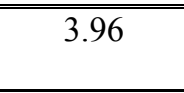 & $\overline{4.18}$ & $\begin{array}{l}0.0290 \\
0.0275 \\
\end{array}$ & $\begin{array}{l}0.0072 \\
0.0071\end{array}$ & $\begin{array}{l}0.0255 \\
0.0242\end{array}$ & $\begin{array}{l}0.0013 \\
0.0013\end{array}$ & $\begin{array}{c}0.5518 \\
0.5390\end{array}$ \\
\hline Rash & 3.96 & 4.18 & $\begin{array}{l}0.0290 \\
0.0275\end{array}$ & $\begin{array}{l}0.0072 \\
0.0071\end{array}$ & $\begin{array}{l}0.0255 \\
0.0242\end{array}$ & $\begin{array}{l}0.0013 \\
0.0013 \\
\end{array}$ & $\begin{array}{l}0.5518 \\
0.5390 \\
\end{array}$ \\
\hline Rasvh & 3.96 & 4.18 & $\begin{array}{l}0.0290 \\
0.0275\end{array}$ & $\begin{array}{l}0.0072 \\
0.0071\end{array}$ & $\begin{array}{l}0.0255 \\
0.0242\end{array}$ & $\begin{array}{l}0.0013 \\
0.0013\end{array}$ & $\begin{array}{l}0.5518 \\
0.5390\end{array}$ \\
\hline Mscev & $\overline{3.97}$ & 3.89 & $\begin{array}{l}0.0270 \\
0.0276\end{array}$ & $\begin{array}{l}0.0078 \\
0.0081\end{array}$ & $\begin{array}{l}0.0185 \\
0.0383\end{array}$ & $\begin{array}{l}0.0016 \\
0.0016\end{array}$ & $\begin{array}{l}0.6342 \\
0.7164\end{array}$ \\
\hline Msceh & 3.04 & 3.39 & $\begin{array}{l}0.0235 \\
0.0211\end{array}$ & $\begin{array}{l}0.0072 \\
0.0072\end{array}$ & $\begin{array}{l}0.0356 \\
0.0141\end{array}$ & $\begin{array}{l}0.0017 \\
0.0017\end{array}$ & $\begin{array}{l}0.6102 \\
0.6207\end{array}$ \\
\hline Mscevh & 3.27 & 3.35 & $\begin{array}{l}0.0232 \\
0.0228\end{array}$ & $\begin{array}{l}0.0066 \\
0.0067\end{array}$ & $\begin{array}{l}0.0225 \\
0.0171\end{array}$ & $\begin{array}{l}0.0015 \\
0.0015\end{array}$ & $\begin{array}{l}0.5694 \\
0.5548\end{array}$ \\
\hline
\end{tabular}

Table 3: Solutions and measures for case a 


\begin{tabular}{|c|c|c|c|c|c|c|c|}
\hline \multirow[b]{2}{*}{ Solutions } & \multicolumn{2}{|c|}{ Objectives } & \multicolumn{5}{|c|}{ Measures (for vertical and horizontal coefficients) } \\
\hline & Horizontal & Vertical & $\mathbf{L}_{1}$ & $\mathbf{L}_{2}$ & MSCE & RAS & $\mathbf{L}_{\infty}$ \\
\hline paymm1 & 2.22 & 4.01 & $\begin{array}{l}0.0279 \\
0.0154\end{array}$ & $\begin{array}{l}0.0077 \\
0.0060\end{array}$ & $\begin{array}{l}0.0402 \\
0.0689\end{array}$ & $\begin{array}{l}0.0027 \\
0.0027\end{array}$ & $\begin{array}{l}0.6608 \\
0.6596\end{array}$ \\
\hline paymm2 & 4.06 & 2.22 & $\begin{array}{l}0.0154 \\
0.0282 \\
\end{array}$ & $\begin{array}{l}0.0060 \\
0.0076 \\
\end{array}$ & $\begin{array}{l}0.0689 \\
0.0584 \\
\end{array}$ & $\begin{array}{c}-0.0171 \\
0.0025 \\
\end{array}$ & $\begin{array}{l}0.6596 \\
0.5232 \\
\end{array}$ \\
\hline compr1 & 2.76 & 3.08 & $\begin{array}{l}0.0214 \\
0.0192\end{array}$ & $\begin{array}{l}0.0065 \\
0.0057\end{array}$ & $\begin{array}{l}0.0344 \\
0.0585\end{array}$ & $\begin{array}{l}0.0025 \\
0.0025\end{array}$ & $\begin{array}{l}0.5233 \\
0.5216\end{array}$ \\
\hline compr2 & 2.95 & 2.92 & $\begin{array}{l}0.0203 \\
0.0205\end{array}$ & $\begin{array}{l}0.0063 \\
0.0058\end{array}$ & $\begin{array}{l}0.0331 \\
0.0580\end{array}$ & $\begin{array}{l}0.0024 \\
0.0024\end{array}$ & $\begin{array}{l}0.5233 \\
0.5216 \\
\end{array}$ \\
\hline met12v & 4.19 & 2.74 & $\begin{array}{l}0.0191 \\
0.0291\end{array}$ & $\begin{array}{l}0.0048 \\
0.0072\end{array}$ & $\begin{array}{l}0.0272 \\
0.0464\end{array}$ & $\begin{array}{l}0.0023 \\
0.0023\end{array}$ & $\begin{array}{l}0.4789 \\
0.5185\end{array}$ \\
\hline met12h & 2.80 & 3.89 & $\begin{array}{l}0.0270 \\
0.0195\end{array}$ & $\begin{array}{l}0.0065 \\
0.0048\end{array}$ & $\begin{array}{l}0.0325 \\
0.0479\end{array}$ & $\begin{array}{l}0.0024 \\
0.0024\end{array}$ & $\begin{array}{l}0.4614 \\
0.4061\end{array}$ \\
\hline met12vh & 3.36 & 3.37 & $\begin{array}{l}0.0234 \\
0.0234\end{array}$ & $\begin{array}{l}0.0054 \\
0.0052\end{array}$ & $\begin{array}{l}0.0294 \\
0.0472\end{array}$ & $\begin{array}{l}0.0023 \\
0.0023\end{array}$ & $\begin{array}{l}0.4732 \\
0.3978 \\
\end{array}$ \\
\hline$\overline{\operatorname{mmaxv}}$ & $\overline{3.82}$ & 2.69 & $\begin{array}{l}0.0187 \\
0.0265\end{array}$ & $\begin{array}{l}0.0062 \\
0.0072\end{array}$ & $\begin{array}{l}0.0321 \\
0.0533\end{array}$ & $\begin{array}{l}0.0025 \\
0.0025\end{array}$ & $\begin{array}{l}0.4596 \\
0.5170\end{array}$ \\
\hline $\operatorname{mmaxh}$ & 2.72 & 3.75 & $\begin{array}{l}0.0261 \\
0.0189\end{array}$ & $\begin{array}{l}0.0066 \\
0.0058\end{array}$ & $\begin{array}{l}0.0381 \\
0.0540\end{array}$ & $\begin{array}{l}0.0027 \\
0.0027\end{array}$ & $\begin{array}{l}0.4611 \\
0.3945 \\
\end{array}$ \\
\hline mmaxvh & 3.28 & 3.04 & $\begin{array}{l}0.0211 \\
0.0228\end{array}$ & $\begin{array}{l}0.0061 \\
0.0062\end{array}$ & $\begin{array}{l}0.0322 \\
0.0493\end{array}$ & $\begin{array}{l}0.0025 \\
0.0025\end{array}$ & $\begin{array}{l}0.4596 \\
0.3860\end{array}$ \\
\hline rasv & 4.30 & 3.62 & $\begin{array}{l}0.0251 \\
0.0299 \\
\end{array}$ & $\begin{array}{l}0.0062 \\
0.0079\end{array}$ & $\begin{array}{l}0.0190 \\
0.0449\end{array}$ & $\begin{array}{l}0.0019 \\
0.0019\end{array}$ & $\begin{array}{l}0.4657 \\
0.6991\end{array}$ \\
\hline $\begin{array}{l}\text { rash } \\
\text { rasvh }\end{array}$ & $\begin{array}{l}4.30 \\
4.30\end{array}$ & $\begin{array}{l}3.62 \\
3.62\end{array}$ & $\begin{array}{l}0.0251 \\
0.0299 \\
0.0251 \\
0.0299\end{array}$ & $\begin{array}{l}0.0062 \\
0.0079 \\
0.0062 \\
0.0079\end{array}$ & $\begin{array}{l}0.0190 \\
0.0449 \\
0.0190 \\
0.0449\end{array}$ & $\begin{array}{l}0.0019 \\
0.0019 \\
0.0019 \\
0.0019\end{array}$ & $\begin{array}{l}0.4657 \\
0.6991 \\
0.4657 \\
0.6991\end{array}$ \\
\hline mscev & 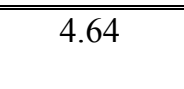 & 3.35 & $\begin{array}{l}0.0233 \\
0.0323\end{array}$ & $\begin{array}{l}0.0067 \\
0.0086\end{array}$ & $\begin{array}{l}0.0164 \\
0.0542\end{array}$ & $\begin{array}{l}0.0020 \\
0.0020\end{array}$ & $\begin{array}{l}0.4987 \\
0.5359\end{array}$ \\
\hline msceh & 10.64 & 8.13 & $\begin{array}{l}0.0565 \\
0.0739\end{array}$ & $\begin{array}{l}0.0292 \\
0.0473\end{array}$ & $\begin{array}{l}0.1299 \\
0.0327\end{array}$ & $\begin{array}{l}0.0031 \\
0.0031\end{array}$ & $\begin{array}{l}4.0647 \\
6.6833\end{array}$ \\
\hline mscevh & 4.62 & 3.74 & $\begin{array}{l}0.0260 \\
0.0321\end{array}$ & $\begin{array}{l}0.0067 \\
0.0090\end{array}$ & $\begin{array}{l}0.0192 \\
0.0391\end{array}$ & $\begin{array}{l}0.0021 \\
0.0021\end{array}$ & $\begin{array}{l}0.5745 \\
0.6848\end{array}$ \\
\hline
\end{tabular}

Table 4 : Solutions and measures for case $b$ 


\begin{tabular}{|l|c|c||c|c|c|c|c||}
\hline \multirow{2}{*}{ Solutions } & \multicolumn{3}{|c|}{ Objectives } & \multicolumn{5}{c|}{ Measures (for vertical and horizontal coefficients) } \\
& Horizontal & Vertical & $\mathbf{L}_{\mathbf{1}}$ & $\mathbf{L}_{\mathbf{2}}$ & $\mathbf{M S C E}$ & $\mathbf{R A S}$ & $\mathbf{L}_{\infty}$ \\
\hline \hline paymm1 & 49.39 & 60.03 & 0.4169 & 0.2661 & 4.6854 & 0.4286 & 35.9516 \\
& & & 0.3430 & 0.2138 & 2.9393 & 0.4286 & 29.0353 \\
\hline \hline paymm2 & 50.63 & 57.92 & 0.4022 & 0.2636 & 2.7298 & 0.4144 & 35.6104 \\
& & & 0.3516 & 0.2118 & 4.3891 & 0.4144 & 28.7579 \\
\hline \hline compr1 & 49.54 & 59.08 & 0.4103 & 0.2659 & 4.4076 & 0.4160 & 35.9516 \\
& & & 0.3440 & 0.2136 & 2.6676 & 0.4160 & 29.0353 \\
\hline compr2 & 49.81 & 58.63 & 0.4072 & 0.2661 & 4.4057 & 0.4162 & 35.9743 \\
& & & 0.3459 & 0.2138 & 2.6676 & 0.4162 & 29.0538 \\
\hline met12v & 58.49 & 66.17 & 0.4595 & 0.2348 & 4.1077 & 0.3832 & 31.5484 \\
& & & 0.4062 & 0.1915 & 3.7668 & 0.3832 & 25.4562 \\
\hline met12h & 56.60 & 65.16 & 0.4525 & 0.2359 & 4.2790 & 0.3884 & 31.4910 \\
& & & 0.3930 & 0.1910 & 3.3999 & 0.3884 & 25.4096 \\
\hline met12vh & 57.71 & 65.66 & 0.4560 & 0.2349 & 4.1983 & 0.3874 & 31.5331 \\
& & & 0.4008 & 0.1913 & 3.6617 & 0.5629 & 25.4438 \\
\hline mmaxv & 72.87 & 90.09 & 0.6256 & 0.3114 & 6.5139 & 0.4081 & 30.0624 \\
& & & 0.5060 & 0.2297 & 4.0565 & 0.4081 & 24.2484 \\
\hline mmaxh & 77.36 & 99.17 & 0.6887 & 0.3478 & 7.7903 & 0.4226 & 37.6842 \\
& & & 0.5372 & 0.2499 & 4.42233 & 0.4226 & 23.9271 \\
\hline mmaxvh & 72.59 & 90.17 & 0.6262 & 0.3112 & 6.4940 & 0.4062 & 30.0624 \\
& & & 0.5041 & 0.2295 & 3.9890 & 0.4062 & 24.2484 \\
\hline rasv & 67.09 & 76.85 & 0.5337 & 0.2493 & 4.4281 & 0.3451 & 32.9343 \\
& & & 0.4659 & 0.2021 & 3.2457 & 0.3451 & 26.5828 \\
\hline rash & 67.09 & 76.85 & 0.5337 & 0.2493 & 4.4281 & 0.3451 & 32.9343 \\
& & & 0.4659 & 0.2021 & 3.2457 & 0.3451 & 26.5828 \\
\hline rasvh & 67.08 & 76.85 & 0.5337 & 0.2493 & 4.4281 & 0.3451 & 32.9343 \\
& & & 0.4659 & 0.2021 & 3.2457 & 0.3451 & 26.5828 \\
\hline mscev & 60.93 & 67.90 & 0.4716 & 0.2790 & 3.2805 & 0.3825 & 38.3053 \\
& & & 0.4232 & 0.2267 & 3.5160 & 0.3825 & 30.9484 \\
\hline msceh & 59.92 & 70.39 & 0.4888 & 0.3104 & 4.7076 & 0.4030 & 42.4357 \\
& & & 0.4161 & 0.2516 & 1.8623 & 0.4030 & 34.3057 \\
\hline mscevh & 57.59 & 66.34 & 0.4607 & 0.3033 & 3.5405 & 0.3974 & 42.1561 \\
& & & 0.4000 & 0.2447 & 2.0857 & 0.3974 & 34.0784 \\
\hline
\end{tabular}

Table 5: Solutions and measures for case c 


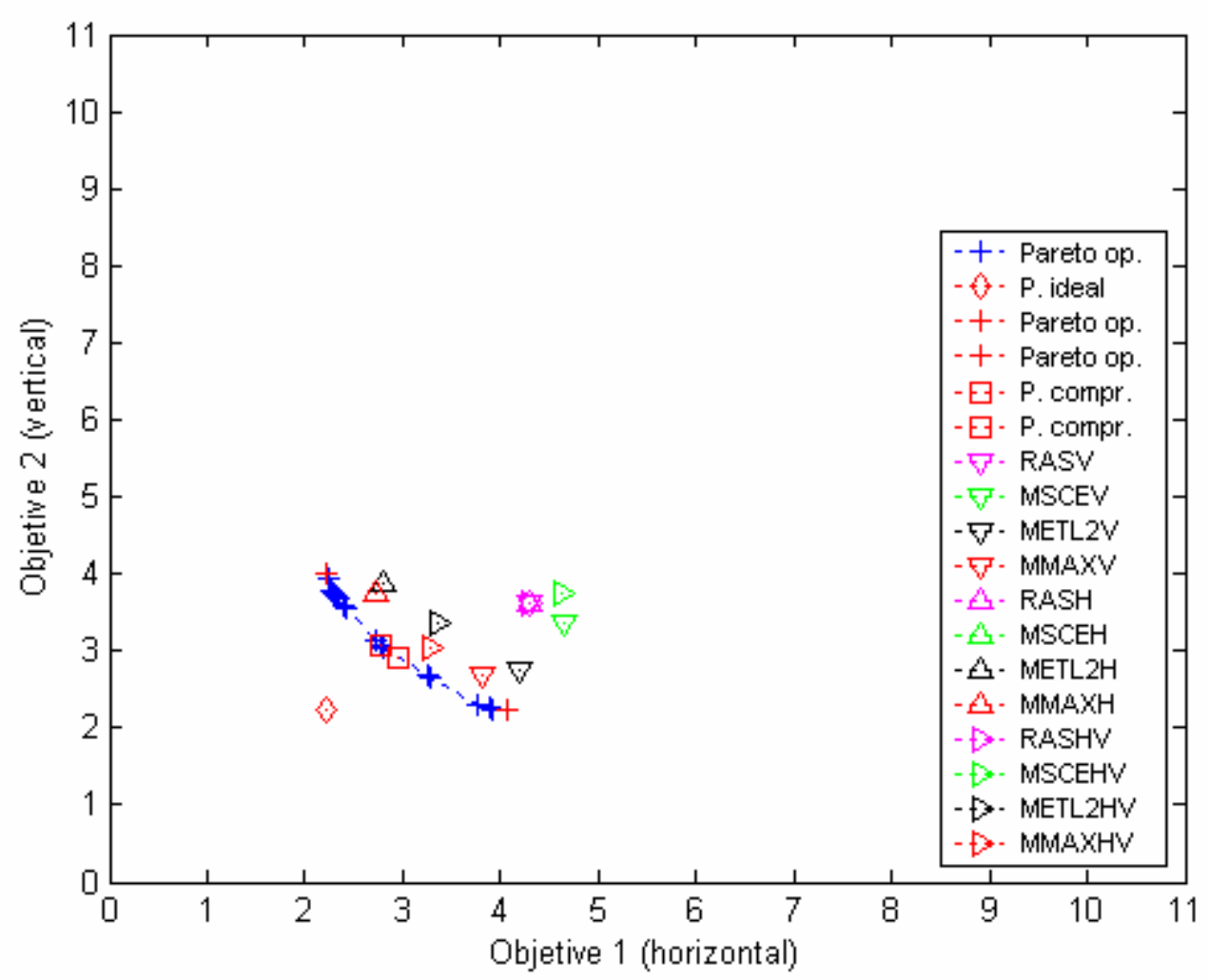

Figure 1: Space of objectives. Case a

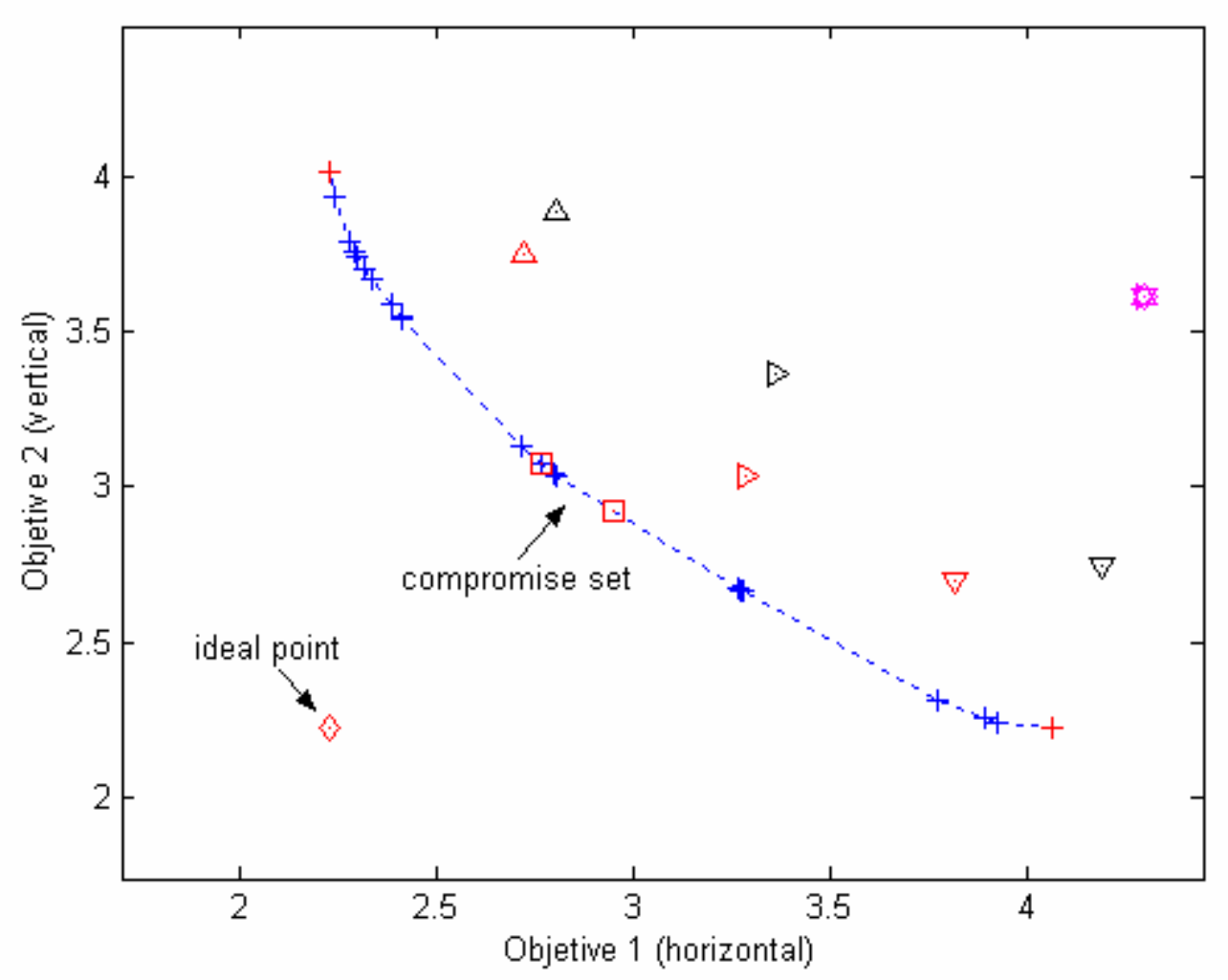

Figure 2: Space of objectives. Case a (enlargement) 


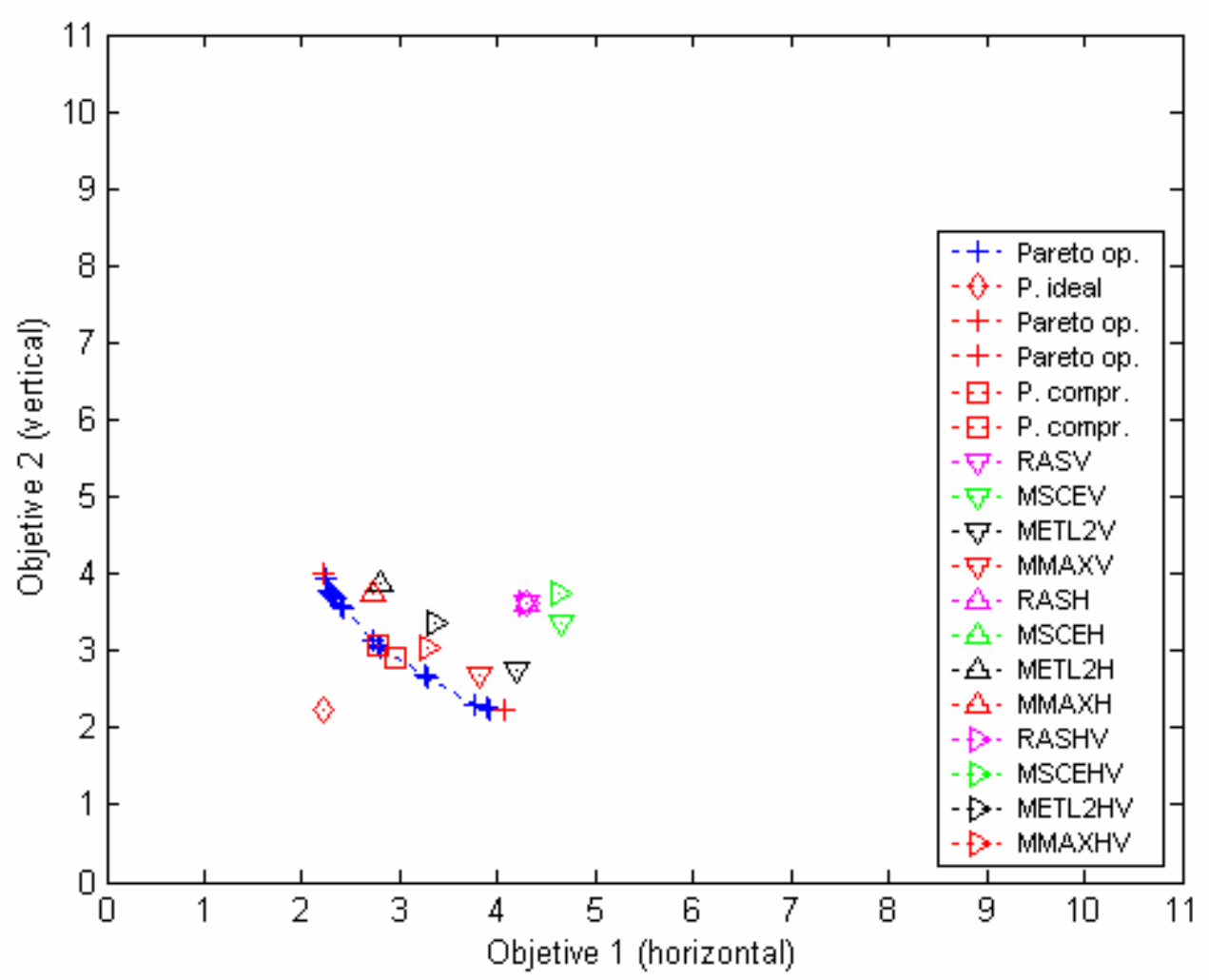

Figure 3: Space of objectives. Case b

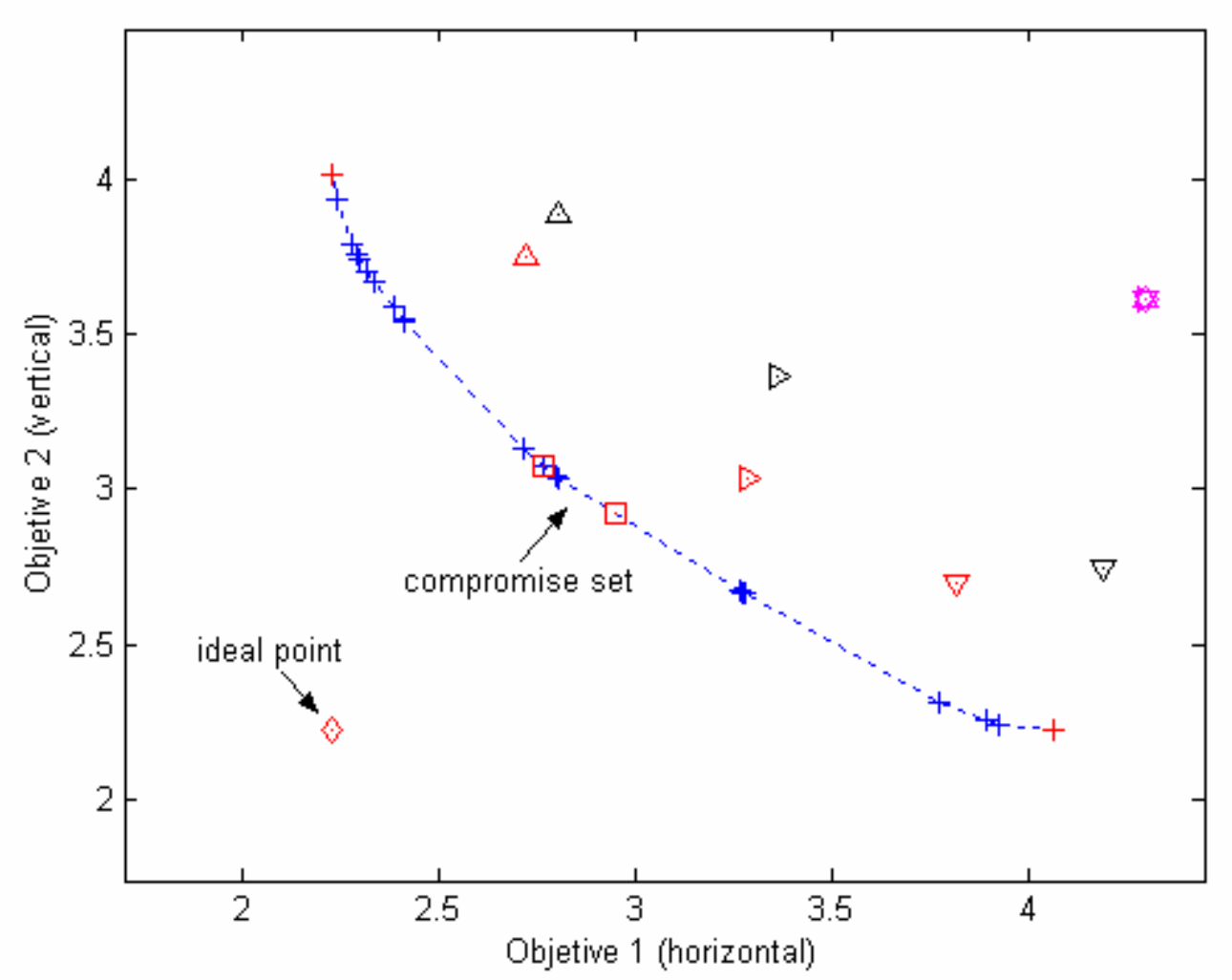

Figure 4: Space of objectives. Case b (enlargement) 


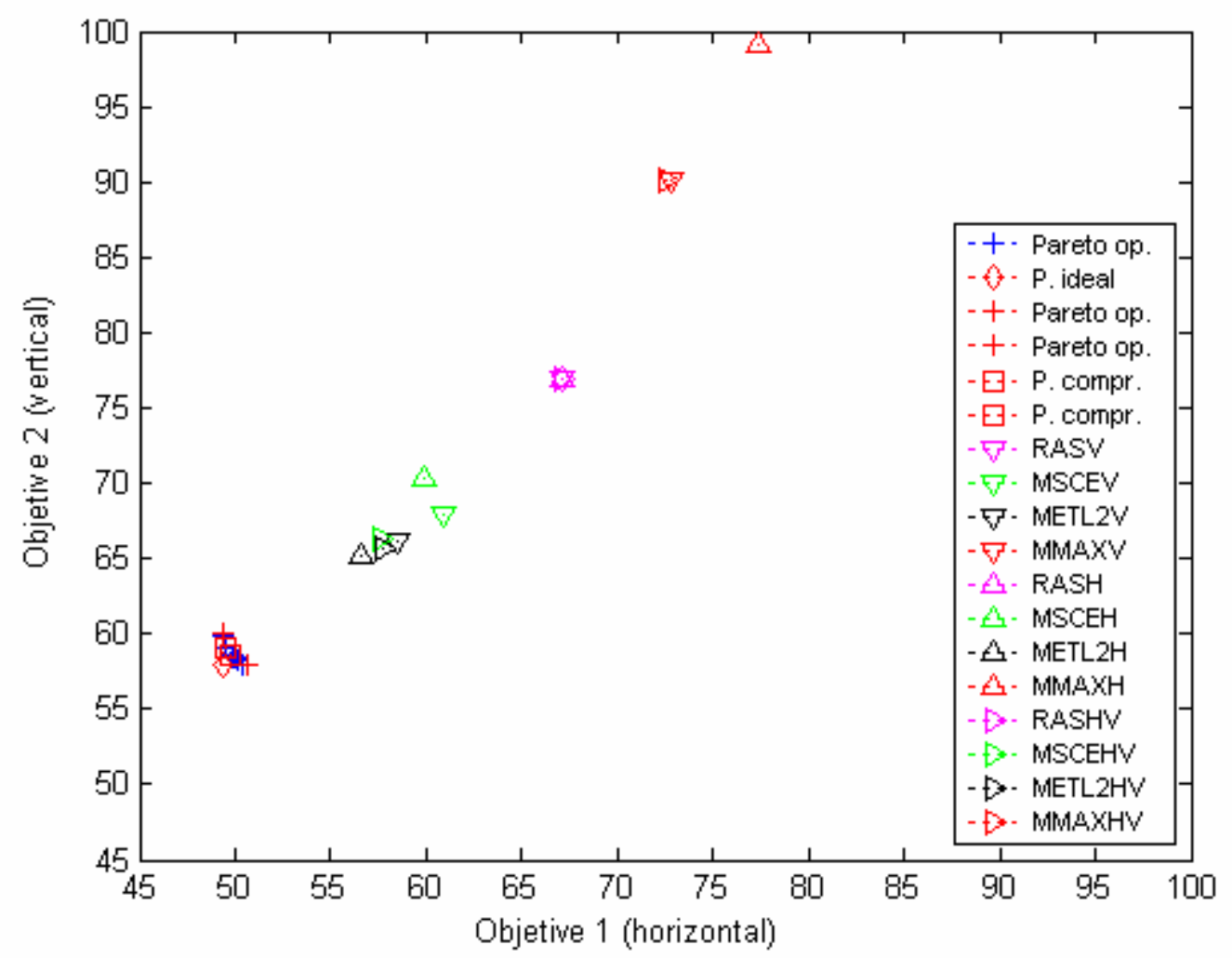

Figure 5: Space of objectives. Case c

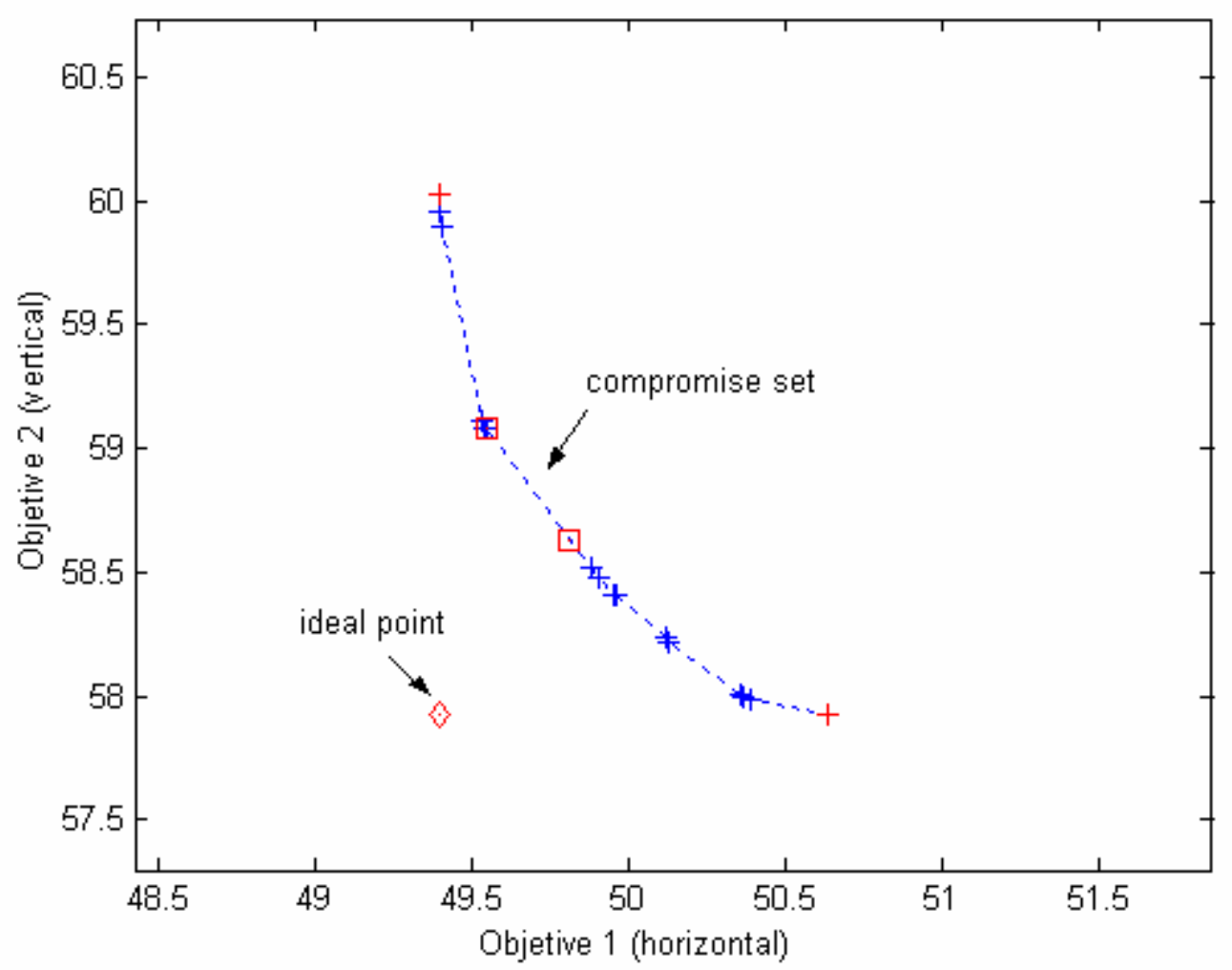

Figure 6: Space of objectives. Case c (enlargement) 